\title{
Editor's introduction to Volume 2
}

Several years ago I attended an international conference of musicologists to take part in a seminar on the subject of the worldwide dissemination of American popular music. At one point in the discussion I asked (I paraphrase), 'Since this phenomenon is so complex, since it interests sociologists, economists, anthropologists, historians, cultural critics, etc. as well as (a few of us) musicologists, can anyone please suggest what methods I should use to study it?' The answer came immediately from a distinguished American musicologist: 'The same method as you would use to study Beethoven. ${ }^{*}$

This is not a musicological journal; nevertheless it seems worth quoting this cautionary tale as a symptom of the methodological disarray, and apathy, afflicting much of the musicological profession and an indication that any search for appropriate theories and methodologies of popular music research should not count on receiving significant help from traditional musicology.

This view seems to me to be confirmed by the treatment of popular music in The New Grove. Elsewhere in this volume (pp. 245-58 below) it is pointed out that, whatever reservations there may be about this treatment, the vastly expanded coverage of popular music in The New Grove, compared to previous music dictionaries, should be enthusiastically welcomed. One can certainly not dissent from that opinion. Nevertheless, the approach that has been adopted needs careful evaluation. A brief survey of the central articles suggests that this approach demonstrates both methodological disarray and apathy. By 'disarray' I refer to the fact that we (everybody) are much less clear than people used to think they were about such questions as, what music is, how to categorise different musical types, what music does to and for people, why they enjoy it, what the best analytical models are for use in studying it. Now such 'disarray' can, if we are conscious of and explicit about it, if it is allowed to energise discussion, be creative. Equally, if it remains unrecognised or is repressed (leading to rigid demarcation between musical categories or types of scholar), it tends

* Not all the discussion was quite so unhelpful. An edited version appears in Heartz and Wade 1981, pp. 570-89. 
towards what I have termed methodological apathy. And this is a close cousin of that simplistic empiricism which denies the existence of a problem: just discover 'the facts' and describe them.

This is not the place to attempt profound theoretical argument. But I would like to put forward three propositions, the validity of which is, I believe, demonstrated by the articles in this volume and also, though not always positively, by The New Grove. Firstly, 'music' and 'society' are not separable concepts: music-making is a social process, and, at the same time, society is constituted by this and other such processes; secondly, 'popular' and other types of music cannot satisfactorily be considered in isolation from each other: making music is a dynamic process involving socially interacting individuals, not an abstract filling of pre-existing categories; and thirdly, purely empirical analytical techniques, which deny the necessity for theory and rely on aggregating easily perceived data, are in themselves not likely to be very useful.

The approach of The New Grove is to demarcate 'popular music' (defined, very loosely, in terms of commercial success and widespread 'comprehensibility', applied to certain musical traditions of the nineteenth and twentieth centuries) and to treat this, or at least its Anglo-American mainstream, in a lengthy, separate article. Related genres (blues, jazz, etc.) are given their own articles, and some aspects of popular music styles are also covered in larger entries devoted to particular countries, cities, etc. There seems to be an implicit assumption that 'art', 'popular' and 'folk' styles can and should be segregated, with various 'ethnic' or 'regional' variants (rhythm and blues, for instance) being located in between these major categories in separate compartments. Thus the 'Popular Music' article discusses music hall but not 'workers' song'; it can say that 'the decades after the Civil War were not important ones for American popular music' - this of the period when the pregenitors of blues must have been forming; and it maintains that rock and roll and rock are not themselves part of popular music but somehow separate genres. The article on Great Britain, having hived off the subject of 'popular music', deals only with 'art' and 'folk' traditions (and the section on 'folk' music, a particularly striking example of the reification of musical categories, discusses only rural song and dance); the article on the USA says a little more about 'popular' genres but not much; while those on Germany and France contain nothing, that for Japan a couple of sentences. Similarly, Nashville rates only ten lines, the entry for San Francisco says nothing about popular music in the area, that for New York (nineteen pages) devotes a page to jazz and a few words to musical comedy, and that for Liverpool only one short paragraph on the 'beat-group cult'. If there is 
any strategy behind this approach, it seems to be a conception of the musical field as divided horizontally into layers, yet this is not argued for, as far as I can find: this type of argument is conspicuously lackingexcept for the excellently stimulating discussion of 'folk' music by Charles Seeger in the USA article.

Within the horizontal stratification, entries and amounts of space seem to be allocated according to a value hierarchy relating to the 'legitimacy' of genres. Jazz, blues, spirituals and gospel music do well, ragtime fairly well, rhythm and blues, country music, soul and reggae far less well, motown grossly inadequately; rock and roll, rock and punk are subsumed within popular music, while there are no entries for beat, zydeko, rockabilly, teenybop, middle-of-the-road, doo-wop or disco, and for swing we are referred to the jazz article, which treats it merely as a background to Ellington and Basie. The entry for gospel song is rather quaintly divided into two parts, the first dealing with 'hymnody' (for which read, written, hence relatively legitimised, texts) and 'performance' (for which read, 'folk', or even 'popular', practice). How delicately the classifier's knife can move!

The same process affects the treatment of technical terms and instruments. Hi-hat and ride cymbals are given three lines at the end of a three-page article on cymbals, while the term 'rim-shot', explained in the entry for drum, is not discussed as a popular music technique. The articles on electronic music and synthesiser have nothing to say about popular music and such terms as 'chorus' and 'slide' (i.e. glissando) do not mention the important popular music usages. 'Riff' and 'walking bass' are defined as jazz terms (very briefly) but their use in other styles is not considered. Vital popular music terms like 'vocal', 'hot', 'cool', 'laid back', 'lick' and 'back beat' have no entries. There is no attempt to include 'folk usage' of terms: for instance, most rock musicians use 'riff' as a synonym, almost, for 'musical idea'. Similarly, the article on the ballad, while containing an account of the 'traditional' ballad which is exemplary in its interdisciplinarity, dismisses British and American broadside ballads in one paragraph, has nothing about ballads in other street song traditions, dispatches what it calls the 'English sentimental ballad' of the nineteenth century in two paragraphs, and deals with twentieth-century usage thus: 'In recent years, particularly since World War II, the word "ballad" has been used to refer to pop songs with sentimental or narrative texts and (usually) a slow tempo.' The most striking examples of all are found when we move to the level of the most fundamental musical terms. The article on harmony does not mention popular music (nor jazz or non-European traditions for that matter); that on melody, after nine pages of discussion, includes a single paragraph which mentions the Beatles, George Gershwin and 
Cole Porter, and pentatonicism in rock; while the entry on rhythm, astonishingly, is completely unaware of popular music's existence.

The introduction of popular music subject-matter has not, then, affected overmuch the general treatment of terminology and methods. Indeed, the horizontal layering of the musical field not only separates inextricably entangled traditions and genres, but also keeps apart differing scholarly methods, those associated, for instance, with historical musicology, folklore and ethnomusicology (while the sociology and psychology of music, safely confined to their own articles, have little effect elsewhere). Popular music, as defined in Grove (together with musical comedy and music hall) receives what is basically an empirical historical treatment, comprising aggregations of obvious 'musical facts' (structural patterns, instrumentation, etc.), assemblies of dates, names and titles, and 'objective' accounts of seemingly important trends and tendencies, changes in dissemination methods, and so on. Little attention is paid to the development of the underlying social and cultural formations, even less to questions of class, and none to ideological aspects of musical production and meaning. There is no 'deep' analysis of musical structures. Problems of the signification and of the pleasure of popular music are equally neglected. The section on 'Europe to World War II' is marked also by an old-fashioned cultural pessimism ('sentimental verses ... easy melody ... stereotyped accompaniments . . . maudlin harmonic progressions . . . little intrinsic merit . . . churned out . . . undemanding communal entertainment ... no serious musical aspirations ... simple, vulgar musical phrases'), from which the rest of the article is blessedly free; and the remaining sections ('North America to 1940', 'Since 1940'), as one would expect from their distinguished author Charles Hamm, are, within the limits set by their criteria, coherent and informative. Still, one reaches the end of the article in possession of lots of data but not much grasp of what the music is really like, what it really does: such illumination is from the start excluded by its method, which is prevented, for example, from seeing in punk rock anything more than the simple continuation of a musical tradition, and can explain the effect of the most successful musicians only in terms of mystification ('they [the Beatles] were successful because they were enormously talented in using familiar musical elements to create songs of such apparent simplicity that one wonders why other musicians could not or did not do just what they were doing . . .'; 'Musicological methods ... cannot adequately explain how he [Stephen Foster] was able to write ... the many ... songs that have been popular for over a century. The means are so simple as to suggest that almost anyone could write such songs; yet no-one but Foster did.'). 
Articles on non-Western genres receive rather different treatment, mainly because they are written by ethnomusicologists or under ethnomusicological influence. Entries for reggae, congolese music, highlife and kwela are brief, unfortunately, though this has at least destroyed any possibility of attempts at narrative comprehensiveness; but they do tend to pay more attention to general social and cultural patterns and developments, and mostly they try to give some account of basic musical characteristics (rather than, or as well as, more superficial style changes). That this need not be confined to 'ethnic' genres is demonstrated by Klaus Wachsmann's excellent article on cabaret. The articles on blues and jazz in some ways stand between the two poles mentioned here. The blues entry, by Paul Oliver, largely eschews detailed discussion of musical structure, but is strong on cultural meaning and function; Max Harrison's jazz entry, conversely, displays considerable insight into musical processes but pays no attention whatever to extra-musical factors (thus, for instance, the occasional mass popularity of jazz is described as 'largely accidental'). Both construct reified conceptions of genre: blues is defined as a folk music ('folk' being undefined) with a separate, isolable evolution, bounded by non-'folk' neighbours such as jazz and rhythm and blues - is this how black Americans perceived their musical field? - while jazz is described as somehow (it is not exactly clear how) set off from, for instance, 'commercial' dance and swing bands, its value as jazz organised in terms of the strength of its search for a certain (Euro-centrically understood) notion of structural 'sophistication'. In both cases the implied historical model - blues is 'folk' music, jazz is 'art' music - is not argued for nor made explicit, and each carries with it its own evaluative criteria: thus, for example, for black singers in recent years, against the development of soul music, to retain a 'blues' style (as defined here) meant retaining their 'integrity as artists'; similarly, the New Orleans jazz revival is the only movement in jazz 'to produce no music of value'.

Theoretical explicitness and self-reflection are important for all musicology: Stephen Blum suggests that 'the question "what does it mean to know a music?" entails that the inquirer attempt to achieve a measure of critical perspective upon the social circumstances and processes which have produced his own education . . . The contextual variables which determine the epistemology of a musician or scholar, as an agent who participates in more than one social group, must themselves limit the techniques and options available for further intellectual (and musical) activity, including any interaction between one's own (socially produced) modes of operation and those exercised by "informants" in a foreign culture.' (Blum 1975, pp. 208-9) We might 
also suggest that, certainly as far as popular music is concerned, the process of learning to ' $k$ now' the music should not isolate the musical object from the historical flux, from social and cultural processes, and from the play of ideology. The articles in the present volume discuss aspects of all these factors - though, obviously, no single collection could pretend to comprehensiveness.

In a sense the first three contributions are (though they are not solely) programmatic: they survey existing theories and methodologies, and set agendas for subsequent discussion. William Brooks argues - precisely as The New Grove does not - for a 'tasteless' musicology, one which abandons the ranking of musical categories and its effects. He writes from the standpoint of a musicologist, but he acknowledges that his proposal will involve musicologists in 'sociological' kinds of research with which they are largely unfamiliar. From the perspective of cultural studies, Iain Chambers surveys the major theoretical traditions which have been applied to popular music and concludes - again - that analysis of musical 'texts' and languages, without consideration of cultural functions and meanings, is unlikely to be profitable. Similarly, Philip Tagg critically examines important analytical methods, this time methods coming mainly from a musicological direction, and, while going further and presenting a model of his own - which, admittedly, deals primarily with the musical object itself - argues that the meaning of this cannot be understood except in terms of extramusical factors.

The remaining articles presented here are organised in two groups, the first concerned to a great extent with diachronic aspects, the second orientated more towards synchronic studies. Analytically, it is often necessary to freeze the historical flow and, artificially, seize hold of the object for study. With popular music this is not always easy. Even since the advent of recordings, which offer reliable 'texts', there is still the difficulty of grasping musical practice. Before this period the problems are still greater. Anthony Bennett discusses some of them, for one specific historical location. Individual musical objects, however, exist in relation to social 'moments' and in relation to other objects and moments in other historical locations. Vladimir Zak is chiefly concerned to investigate the relationship of continuity and change in the structure of popular song melody, drawing material from a wide historical spectrum. Deriving his approach from Boris Asaf'ev's 'intonation theory', he sees the structure of change and continuity in music as a response to that in social evolution. Compatible conclusions, from an ethnomusicological perspective, are reached by David Coplan, whose study of rural-to-urban developments in South African popular music suggests that aspects of conti- 
nuity and of change can be understood only by analysing both musical and social processes.

Zak and Coplan have as contexts whole cultures, over long historical spans. More localised studies inevitably meet the problem of categorising styles and genres. How can we define genres (without falling into the trap of positivist compartmentalisation)? Franco Fabbri offers a method which sees genres as located at points where sociological factors and intramusical rules and conventions cross. Analysis of such points has in recent years led to several attempts to establish correspondences or homologies between the structure of specific musical genres and styles and the wider social reality of specific groups. Paul Oliver sees the relationship between black American cultural patterns and black American music, in particular blues, as lying in shared binary structures. Structure is the subject of John Shepherd's account of the social meaning of Afro-American musics and their derivatives, notably rock. Working on a large scale, Shepherd's concern is to outline a sociology of the musical language of these forms. Inevitably the question of subculture is involved here, for the proposed homology between Afro-American forms and the social reality of their audiences works against, is set in relation to, the homology between the nature of the general Western musical tradition and the mode of consciousness to which the social reality of capitalist society gives rise.

It could be argued that the development of this reality climaxes in the emergence of what is often called 'mass culture'. At any rate, in the twentieth century no musical subculture can exist except in relation to the processes of mass culture. Debate around this relationship is old established, and the final two articles take up the debate, adopting contrasting viewpoints. Max Paddison exposes some of the flaws in T. W. Adorno's view of popular music, which saw the ideological power of the 'culture industry' as dominant, preventing any critical 'popular' response, but he concludes that in the end the battle against the industry has been lost; conversely, Peter Wicke, in an approach more like that of Adorno's colleague and - on this issue - adversary, Walter Benjamin, analyses the monopolistic, alienating tendencies of advanced capitalist society, but nevertheless sees within the development of mass cultural processes the potential for new, democratic, liberating modes of creativity. A music like rock, he argues, is a product of this contradiction.

Wicke's insistence that, to analyse mass cultural forms, methods new to traditional musicology and aesthetics will be necessary, returns us to themes broached in the first essays in this collection - and also, ironically, to The New Grove, which tells us there is a tendency . . . towards the replacement of traditional musicology by a sociology of 
music, which, whatever its orientation, aims not to "explain" individual "works" hermeneutically, systematically, or historically, but to analyse the social effects of music, to explain its social function as the basis for all forms of production and consumption' ( $K$. Boehmer, article on 'Sociology of Music', vol. 17, p. 437). 'Production' and 'consumption' will be the subjects of subsequent issues of this journal. Meanwhile, returning to the subject of the cautionary tale with which I began this introduction, we can perhaps contemplate the evolution of a 'tasteless' musicology, in which, after all, Beethoven and popular music will require the same analytical methods - only the two scholarly protagonists in this imitative relationship may find their roles reversed.

\section{References}

Blum, S. 1975. 'Towards a social history of musicological technique', Ethnomusicology, 19:2, pp. 207-31

Heartz, D. and Wade, B. (eds.) 1981. Report of the Twelfth Congress 1977, proceedings of the congress of the International Musicological Society (Kassel/Basel/London)

Sadie, S. (ed.) 1981. The New Grove Dictionary of Music and Musicians (London) 